\title{
MEDIA PAPAN TRIPEL PYTHAGORAS DALAM PEMBELAJARAN MATEMATIKA DI MTS DARUL ULUM BANDUNG JOMBANG
}

\section{PYTHAGORAS TRIPLE BOARD MEDIA IN LEARNING MATHEMATICS AT MTS DARUL ULUM BANDUNG JOMBANG}

\author{
Syarifatul Maf'ulah ${ }^{1 *}$, Sri Ratna Zulianti², Masfufah ${ }^{3}$ \\ ${ }^{1}$ STKIP PGRI Jombang \\ ${ }^{2}$ MI Al Urwatul Wutsqo 1 Jombang \\ ${ }^{3}$ MTs Darul Ulum Bandung Jombang \\ *Email: syarifatul.m@gmail.com \\ (Diterima 05-05-2021; Disetujui 05-08-2021)
}

\begin{abstract}
ABSTRAK
Permasalahan yang dihadapi siswa MTs Darul Hikmah Bandung Jombang adalah kesulitan memahami materi matematika, salah satunya materi Phytagoras. Hal tersebut disebabkan karena sifat matematika yang abstrak dan didukung dengan metode yang digunakan guru adalah ceramah (berdasarkan hasil observasi). Dengan demikian, melalui kegiatan pengabdian, tim pengabdi menciptakan suatu media pembelajaran yang diharapkan bisa membantu kesulitan siswa dalam memahami materi Phytagoras dalam pembelajaran matematika, yaitu Media Papan Tripel Phytagoras. Metode pengabdian ini melalui 3 tahap kegiatan, yaitu persiapan, pelaksanaan, dan evaluasi. Tahap persiapan berisi analisis kebutuhan mitra (dalam hal ini adalah MTs Darul Hikmah Diwek), perizinan dan pengajuan kerja sama, serta menciptakan media Papan Tripel Phytagoras. Tahap pelaksanaan berarti menggunakan/memanfaatkan media tersebut dalam pembelajaran matematika, sedangkan tahap evaluasi berisi pemberian tes materi Phytagoras untuk mengetahui kebermanfaatan dari media Papan Tripel Phytagoras. Hasil kegiatan pengabdian adalah tim pengabdi telah memanfaatkan media Papan Triple Phytagoras dalam pembelajaran. Pertama, pendahuluan, dalam hal ini menyampaikan tujuan pembelajaran. Kemudian kegiatan inti, yaitu menjelaskan terlebih dulu materi Phytagoras secara ceramah dan dilanjutkan dengan pemanfaatan Media Papan Tripel Phytagoras untuk memperkuat pemahaman siswa terkait materi Phytagoras. Setelah itu tim pengabdi memberikan tes. Hasilnya menunjuukan jika lebih baik setelah diterapkannya media papan phytagoras
\end{abstract}

Kata kunci: Media Papan Triple Phytagoras, Pembelajaran Matematika

\section{ABSTRACT}

The problem that one of the students at MTs Darul Hikmah Bandung Jombang is having difficulty understanding mathematics material, one of which is the Pythagorean material. This is due to the abstract nature of mathematics and is supported by the method the teacher uses is lectures (based on observations). Thus, through community service activities, the service team creates a learning medium that is expected to help students understand the Pythagorean material in mathematics learning, namely the Pythagorean Triple Board Media. This service method goes through 3 stages of activities, namely preparation, implementation, and evaluation. The preparation stage contains an analysis of partner needs (in this case is MTs Darul Hikmah Diwek), licensing and proposals for cooperation, as well as creating Pythagoras Triple Board media. The implementation stage means using the media in learning mathematics, while the evaluation stage consists of giving the Pythagorean test to see the usefulness of the Pythagorean Triple Board media. The result of this service activity was that the service team had used the Pythagoras Triple Board media in learning. First, introduction, in this case convey the learning objectives. Then the core activity, namely explaining in advance, the Pythagorean material in lectures and analysis using the Pythagorean Triple Board Media to understand students' understanding of the Pythagorean material. After that the service team gave the test. The results show if it was better after the application of Pythagorean board media.

Keywords: Pythagoras Triple Board Media, Mathematics Learning 


\section{PENDAHULUAN}

Matematika merupakan salah satu ilmu yang dipelajari di setiap jenjang pendidikan, oleh karena itu matematika diajarkan dari pendidikan dasar hingga perguruan tinggi. Hal ini disebabkan matematika sangat dibutuhkan dan berguna dalam kehidupan sehari-hari. Matematika berfungsi mengembangkan kemampuan menghitung, mengukur, dan menyelesaikan permasalahan dalam kehidupan sehari-hari.

Semua kemampuan ini bertujuan agar siswa dapat berperan aktif, baik dalam pembelajaran maupun dalam kehidupan sehari-hari. Menurut Wardhani (2008), tujuan mata pelajaran matematika diuraikan sama untuk semua satuan pendidikan, yaitu agar siswa memiliki kemampuan: (1) Memahami konsep matematika, menjelaskan keterkaitan antarkonsep, dan mengaplikasikan konsep atau algoritma secara luwes, akurat, efisien, dan tepat dalam pemecahan masalah; (2) Menggunakan penalaran pada pola dan sifat, melakukan manipulasi matematika dalam membuat generalisasi, menyusun bukti, atau menjelaskan gagasan dan pernyataan matematika; (3) Memecahkan masalah yang meliputi kemampuan memahami masalah, merancang model matematika, menyelesaikan model, dan menafsirkan solusi yang diperoleh; (4) Mengkomunikasikan gagasan dengan simbol, tabel, diagram, atau media lain untuk memperjelas keadaan atau masalah; dan (5) Memiliki sikap menghargai kegunaan matematika dalam kehidupan, yaitu rasa ingin tahu, perhatian, dan minat dalam mempelajari matematika, serta sikap ulet dan percaya diri dalam pemecahan masalah.

Salah satu tujuan pembelajaran matematika yang disebutkan di atas adalah kemampuan memahami konsep matematika. Matematika sering dianggap sebagai mata pelajaran yang sulit karena sifatnya yang abstrak, salah satunya materi teorema Pythagoras. Pemahaman terhadap materi teorema Pythagoras perlu ditekan pada siswa sejak dini karena merupakan pengetahuan dasar dalam belajar matematika lebih lanjut dalam kehidupan sehari-hari. Kesulitan yang dialami siswa mengakibatkan rendahnya pemahaman siswa pada materi teorema Pythagoras. Hal ini menunjukkan bahwa masih rendahnya kemampuan pemahaman konsep matematika siswa. Berdasarkan hasil wawancara dengan guru matematika kelas VIII diperoleh informasi bahwa mata pelajaran matematika kelas VIII di MTs Darul Ulum Bandung Diwek Jombang menggunakan metode pembelajaran konvensional yaitu metode pembelajaran yang berpusat langsung dari guru. Pada proses pembelajaran, siswa kurang mampu menggunakan konsep yang ada untuk menyelesaikan soal-soal berbentuk masalah dalam kehidupan sehari-hari dikarenakan siswa lebih banyak menghapal konsep untuk menyelesaikannya dan siswa 
hanya 3 bisa mengerjakan soal dengan tipe yang sama diberikan oleh guru karena mereka kurang memahami dengan tipe soal yang berbeda dari contoh yang diberikan oleh guru. Salah satu materi yang sulit dipahami siswa yaitu teorema Pythagoras. Hal ini disebabkan karena pada materi teorema Pythagoras siswa harus mengerti konsep segitiga. Selain itu, siswa harus bisa mengkuadratkan angka dan mencari akar dari hasil kuadrat tersebut dan siswa kurang memahami cara penyelesaian soal cerita karena memerlukan pemahaman konsep terhadap permasalahan yang diberikan. Siswa terkadang kurang memahami apa yang dimaksud dalam soal.

Hal ini dapat disimpulkan bahwa kemampuan siswa MTs Darul Ulum Bandung Diwek Jombang dalam menyelesaikan soal-soal matematika sangat lemah. Menurut Nugraheni dan Sugiman (2013), bahwa keberhasilan pembelajaran ditentukan juga oleh pemahaman konsep. Mempelajari konsep matematika itu ibarat membangun sebuah gedung bertingkat, lantai kedua dan selanjutnya tidak akan terwujud dengan baik jika fondasi dan lantai sebelumnya yang menjadi tumpuan tidak terbangun dengan kuat. Begitu pula dalam mempelajari konsep matematika, karena dalam konsep matematika selalu ada konsep prasyarat yang digunakan sebagai dasar untuk memahami konsep selanjutnya.

Dalam mempelajari matematika, pemahaman konsep sangat penting untuk siswa karena konsep matematika yang satu dengan yang lain berkaitan sehingga untuk mempelajarinya harus runtut dan berkesinambungan. Jika siswa telah 4 memahami konsep-konsep matematika maka akan memudahkan dalam mempelajari konsep-konsep berikutnya yang lebih kompleks. Pemahaman konsep merupakan suatu aspek yang sangat penting dalam pembelajaran, karena dengan kemampuan pemahaman konsep siswa dapat menyelesaikan permasalahan dan mengembangkan kemampuannya dalam setiap materi pelajaran. Namun, menurut Murizal, dkk (2012), bahwa pada kenyataannya banyak siswa yang kesulitan dalam memahami konsep matematika. Bahkan mereka kebanyakan tidak memaknai matematika dalam bentuk nyata. Menurut Widyastuti dan Pujiastuti (2014), hal tersebut didukung dengan kenyataan yang terjadi di lapangan yang menunjukan hasil: (1) Aktivitas siswa lebih banyak mendengarkan penjelasan guru dalam mengikuti pembelajaran khususnya matematika. Jelas terlihat bahwa siswa hanya aktif dalam hal mencatat. Dengan guru berperan sebagai subjek pembelajaran, komunikasi antara guru dan siswa berjalan kurang efektif; (2) Pembelajaran matematika lebih difokuskan pada hasil yaitu nilai daripada proses pembelajaran; (3) Pembelajaran seringkali tidak melibatkan siswa secara langsung dalam mengkonstruksi pengetahuan; (4) Pada saat pembelajaran jarang terlihat terjadi komunikasi efektif dua arah antara guru dan siswa. Hal ini terlihat 
dengan sering diamnya siswa dan tidak mengajukan pertanyaan ataupun mengemukan pendapat mereka kepada guru; (5) Metode atau pendekatan yang digunakan lebih banyak menggunakan ceramah dan latihan soal. Selanjutnya penyebab siswa kesulitan dalam memahami materi phytagoras salah satunya karena sifatnya yang abstrak. Sehingga diperlukan media atau alat peraga yg berfungsi dapat membantu siswa dalam memahami konsep phytagoras, yaitu media Papan Tripel Pythagoras. Hal ini menunjukkan bahwa pembelajaran matematika dirasakan siswa kurang menarik bagi siswa. Untuk mencapai pemahaman konsep peserta didik dalam matematika dapat dilakukan dengan penggunaan media papan tripel Pythagoras. Dengan demikian, dari berbagai uraian di atas, maka tim pengabdi mengambil judul "Pemanfaatan Media Papan Tripel Phytagoras Pembelajaran Matematika di MTs Darul Ulum Bandung Jombang”.

\section{BAHAN DAN METODE}

Adapun metode pelaksanaan dalam kegiatan pengabdian yang telah dilakukan adalah sebagai berikut:

\section{Tahap Persiapan}

a. Analisis kebutuhan sasaran/mitra

Tim Pengabdi menganalisis kebutuhan dan permasalahan MTs Darul Hikmah Bandung Jombang. Permasalahan yang dihadapi adalah siswa sulit memahami materi phytagoras. Sehingga tim pengabdi mencoba memberikan solusi melalui pengadaan alat peraga dalam memahamkan konsep phytagoras.

b. Perizinan dan Pengajuan Kerja Sama

Perizinan dan kerja sama dilakukan setelah analisis kebutuhan dilakukan. Pihak Sekolah telah mengizinkan dan menerima solusi yang ditawarkan oleh tim pengabdi, sehingga terjalin kerjasama.

c. Menciptakan Media Papan Tripel Phytagoras

Tahap selanjutnya adalah menciptakan/membuat alat peraga/media Papan Triple Phytagoras. Tim pengabdi membuat alat peraga tersebut. Berikut ini adalah Gambar 1 yaitu gambar media Papan Triple Phytagoras. 


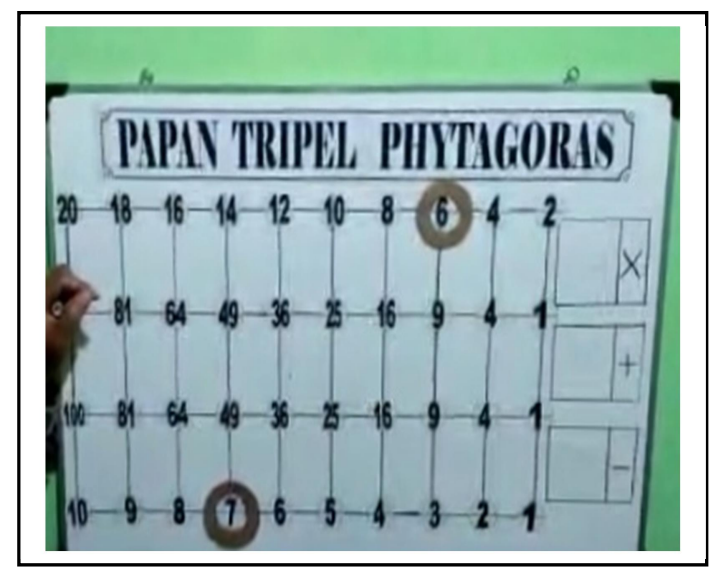

Gambar 1. Media Papan Tripel Phytagoras

\section{Tahap Pelaksanaan}

Tim pengabdi melaksanakan kegiatan pengabdian dengan memanfaatkan media Papan Tripel Phytagoras dalam pembelajaran matematika.

\section{Tahap Evaluasi}

Untuk mengevaluasi kebermanfaatan media Papan Tripel Phytagoras dalam pembelajaran matematika, maka tim menggunakan tes hasil belajar materi phytagoras yang diberikan setelah media diterapkan dalam pembelajaran..

\section{HASIL DAN PEMBAHASAN}

Hasil dan pembahasan ini, tim pengabdi akan menguraikan tentang penggunaan media Papan Triple Phyatoras dalam pembelajaran. Penjelasannya adalah sebagai berikut:

Pembelajaran dilaksanakan secara daring. Hal ini dikarenakan Indonesia (khususnya Kabupaten Jombang) sedang mengalami pandemik Covid-19, sehingga pemerintah meniadakan pertemuan/ pembelajaran tatap muka di sekolah.

Pertemuan pertama tanggal 16 November 2020, siswa mengikuti pembelajaran selama 2 jam pelajaran terkait pengenalan pengertian teorema Pythagoras. Pembelajaran diawali dengan pengiriman video tentang pengertian, teorema pythagoras melalui WhatsApp Group kemudian dilanjut dengan tanya jawab dengan siswa. Pertemuan kedua dilaksanakan tanggal 23 November 2020 pengiriman video yang kedua untuk untuk menjelaskan penggunaan media papan tripel pythagoras. Kemudian dilanjut dengan tes kemampuan akhir siswa di akhir pertemuan. 
Adapun proses penerapan media Papan Tripel Phytagoras adalah sebagai berikut:

\section{Membuka proses belajar mengajar}

Sesuai jadwal pelajaran yang telah dikirim oleh guru kepada siswa, maka guru membuat WhatsApp Group untuk memudahkan komunikasi antar guru dan siswa. Guru selalu memulai pembelajaran dengan mengucap salam, menanyakan kabar siswa dan mengajak untuk berdoa bersama.

\section{Mengingatkan materi sebelumnya}

Pada kegiatan ini tim pengabdi mengingatkan kembali tentang materi segitiga sikusiku.

\section{Menjelaskan unsur-unsur segitiga}

Guru menjelaskan: Pythagoras menyatakan bahwa: “ untuk setiap segitiga siku-siku berlaku kuadrat panjang sisi miring (hipotenusa) sam dengan jumlah kuadrat sisi sikusikunya”.

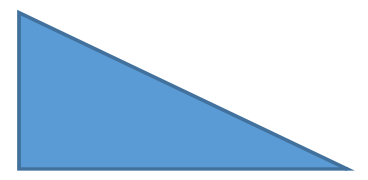

Gambar 2. Segitiga siku-siku

Berdasarkan Gambar 2 di atas yang merupakan sisi miring adalah sisi c(sisi yang berhadapan dengan sudut siku-siku),sedangkan sisi a dan $b$ adalah sisi tegak lurus. Berdasarkan teorema Pythagoras maka diperoleh hubungan $: c^{2}=a^{2}+b^{2}$

\section{Memperkenalkan media papan tripel pythagoras}

Triple Pythagoras adalah tiga bilangan asli yang memenuhi rumus teorema Pythagoras. Dengan kata lain, triple Pythagoras merupakan tiga bilangan yang tepat untuk menyatakan panjang sisi-sisi suatu segitiga siku-siku. Jadi, ketiga bilangan dalam triple Pythagoras menyatakan sisi miring, sisi depan, dan sisi apit pada segitiga siku-siku. Misal $\mathrm{p}>\mathrm{q}>\mathrm{r}$ dengan $\mathrm{p}, \mathrm{q}$, dan $\mathrm{r}$ adalah bilangan asli dan berlaku persamaan $\mathrm{p}^{2}+\mathrm{q}^{2}=$ $\mathrm{r}^{2}$, maka $\mathrm{p}, \mathrm{q}$, dan $\mathrm{r}$ merupakan triple Pythagoras.

Cara mengoperasikan media Papan Tripel Phytagoras, yaitu sebagai berikut.

Langkah 1: Letakkan dua bilangan sembarang pada baris pertama. Misalnya disajikan pada Gambar 3. 


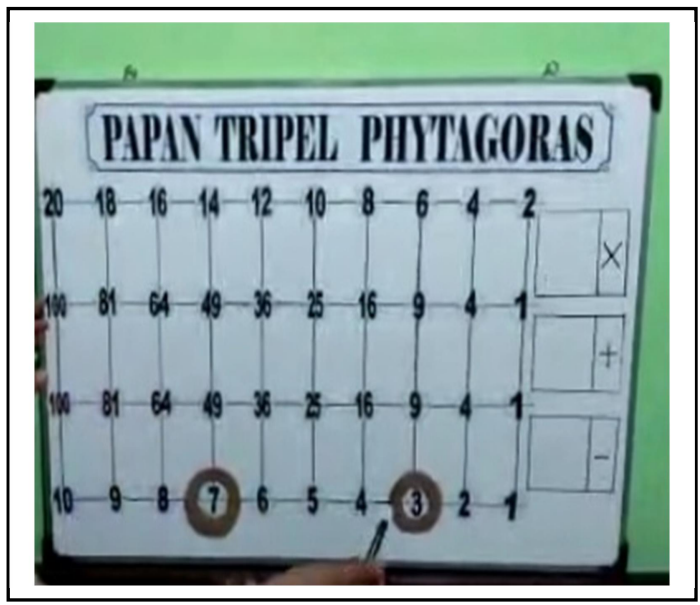

Gambar 3. Contoh langkah 1

Langkah 2: Arahkan kebaris kedua kemudian kurangkan kedua bilangan yang ditemukan dan tulis di kotak yang disediakan (bisa dilihat pada Gambar 4).

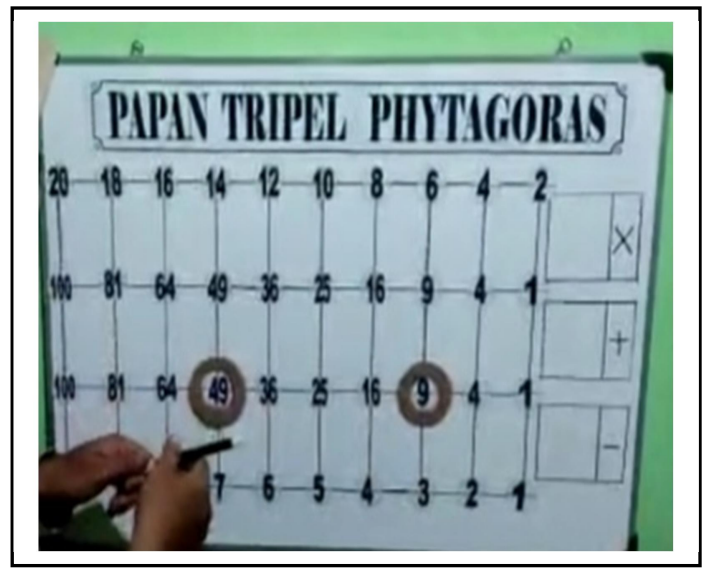

Gambar 4. Gambaran langkah 2

Langkah 3: Arahkan ke baris ketiga kemudian jumlahkan kedua bilangan yang ditemukan dan tulis di kotak yang disediakan. Gambaran langkah 3 bisa dilihat pada Gambar 5 berikut.

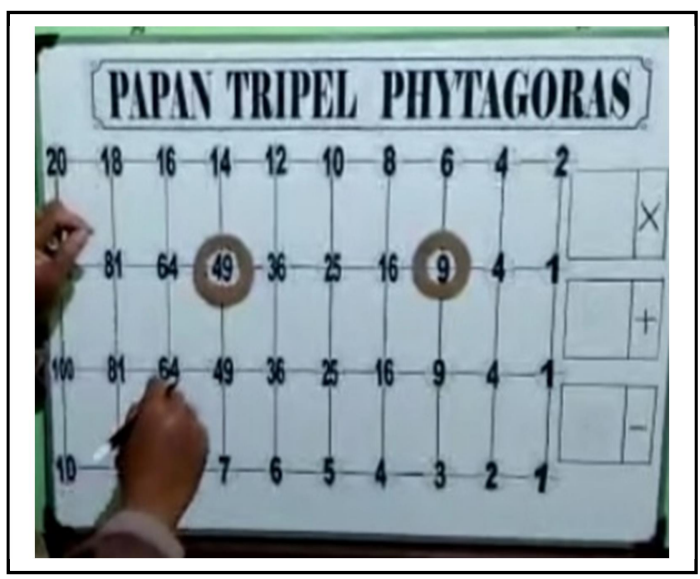

Gambar 5. Gambaran langkah 3 
Langkah 4: Tarik ke atas salah satu, yang lainnya kebawah atau sebaliknya kalikan kedua bilangan yang ditemukan dan tulis di kotak yang disediakan. Gambaran langkah 4 ini disajikan pada Gambar 6 berikut.

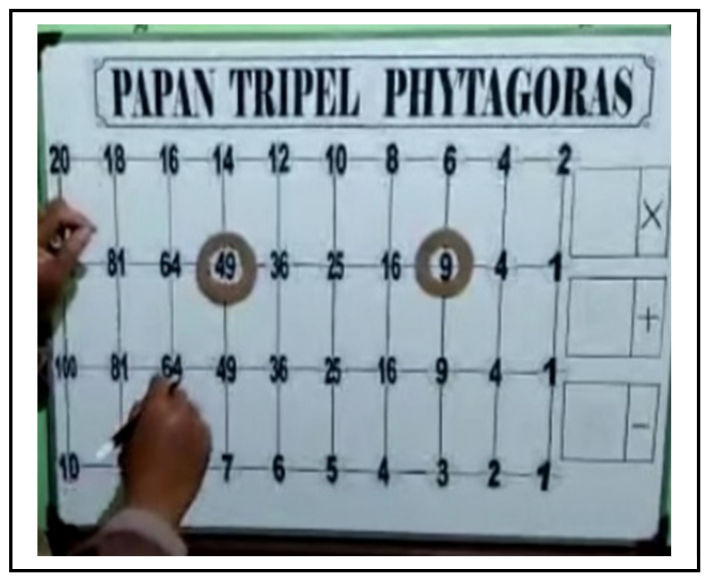

Gambar 6. Gambaran langkah 4

Ketiga bilangan yang ditemukan adalah tripel Phytagoras.

\section{Memberikan penguatan}

Pada kegiatan ini, tim pengabdi memberikan penguatan/penekanan materi phytagoras yang baru saja dipelajari.

\section{Menarik kesimpulan}

Pada kegiatan ini, tim pengabdi menyampaikan kesimpulan/inti materi phytagoras yang baru saja dipelajari.

Selanjutnya untuk melihat kebermanfaatan media Papan Triple Phytagoras, maka tim pengabdi memberikan tes hasil belajar kepada siswa. Skor tes hasil belajar terlihat pada Tabel 1.

Tabel 1. Skor tes hasil belajar sebelum dan sesudah menggunakan media

\begin{tabular}{ccccccccc}
\hline No & $\begin{array}{c}\text { Skor } \\
\text { sebelum }\end{array}$ & $\begin{array}{c}\text { Skor } \\
\text { sesudah }\end{array}$ & No & $\begin{array}{c}\text { Skor } \\
\text { sebelum }\end{array}$ & $\begin{array}{c}\text { Skor } \\
\text { sesudah }\end{array}$ & No & $\begin{array}{c}\text { Skor } \\
\text { sebelum }\end{array}$ & $\begin{array}{c}\text { Skor } \\
\text { sesudah }\end{array}$ \\
\hline 1 & 55.0 & 80.0 & 12 & 67.5 & 87.5 & 23 & 55.0 & 87.5 \\
2 & 75.0 & 77.5 & 13 & 55.0 & 87.5 & 24 & 67.5 & 87.5 \\
3 & 67.5 & 87.5 & 14 & 55.0 & 87.5 & 25 & 55.0 & 87.5 \\
4 & 55.0 & 87.5 & 15 & 55.0 & 80.0 & 26 & 55.0 & 87.5 \\
5 & 55.0 & 87.5 & 16 & 67.5 & 97.5 & 27 & 67.5 & 87.5 \\
6 & 62.5 & 87.5 & 17 & 55.0 & 95.0 & 28 & 62.5 & 90.0 \\
7 & 55.0 & 87.5 & 18 & 67.5 & 97.5 & 29 & 80.0 & 87.5 \\
8 & 80.0 & 75.0 & 19 & 55.0 & 82.5 & 30 & 55.0 & 72.5 \\
9 & 55.0 & 87.5 & 20 & 55.0 & 95.0 & 31 & 55.0 & 77.5 \\
10 & 55.0 & 87.5 & 21 & 75.0 & 82.5 & 32 & 55.0 & 95.0 \\
11 & 62.5 & 87.5 & 22 & 67.5 & 95.0 & 33 & 55.0 & 95.0 \\
\hline & & Rata-rata & & & & 61,06 & 87.12
\end{tabular}


Berdasarkan Tabel 1 diperoleh informasi bahwa rata-rata sebelum diterapkan media Papan Tripel Phytagoras sebesar 61,06. Sedangkat rata-rata setelah diterapkan media Papan Tripel Phytagoras sebesar 87,12. Ini berarti hasil belajar menjadi lebih baik setelah diterapkannya media Papan Tripel Phytagoras.

\section{KESIMPULAN DAN SARAN}

Kesimpulan kegiatan ini adalah: (1) Pemanfaatan media Papan Tripel Phytagoras merupakan bentuk penerapan media dalam pembelajaran matematika. Tim pengabdi menciptakan media tersebut berdasarkan permasalahan di lapangan. Kemudian memanfaatkan media tersebut dalam pembelajaran sebagai bentuk dari solusi yang diberikan. Prosesnya berjalan dengan baik. Hasil belajar siswa menjadi lebih baik setelah diterapkannya media Papan Tripel Phytagoras.

\section{DAFTAR PUSTAKA}

Murizal dkk. (2012). Pemahaman Konsep Matematis dan Model Pembelajaran Quantum Teaching. Jurnal Pendidikan Matematika, 1(1), 19-23.

Nugraheni, E. \& Sugiman, S. (2013). Pengaruh Pendekatan PMRI terhadap Aktifitas dan Pemahaman Konsep Matematika Siswa SMP. PYTHAGORAS: Jurnal Pendidikan Matematika, 8(1), 101-108.

Wardhani, S. (2008). Analisis SI dan SKL Mata Pelajaran Matematika SMP/MTs. Untuk Optimalisasi Tujuan Mata Pelajaran Matematika. Yogyakarta: Depdiknas

Widyastuti, N. S. \& Pujiastuti, P. (2014). Pengaruh Pendidikan Matematika Realistik Indonesia (PMRI) terhadap Pemahaman Konsep dan Berpikir Logis Siswa. Jurnal Prima Edukasia, 2(2), 183-193. 